\title{
LE MÂLE DE PTERIDOPHARYNX OMOENSIS NEVEU-LEMAIRE PARASITE DU RHINOCÉROS AFRICAIN \\ (RHINOCEROS BICORNIS)
}

\author{
Par M. NEVEU-LEMAIRE
}

Au cours d'une étude sur les Strongylidés du rhinocéros africain (1), nous avons décrit, dans la sous-famille des Cylicostominæ, sous le nom de Pteridopharynx omoensis Neveu-Lemaire, 1924, une espèce, dont nous n'avions rencontré que des exemplaires femelles. Tout récemment, en examinant d'autres échantillons provenant du même rhinocéros, nous avons eu la chance d'observer un individu mâle. Nous en donnerons une brève description, accompagnée de quelques figures.

Description. - Le corps est cylindroïde, d'un diamètre presque constant, un peu moindre cependant au voisinage des extrémités qui sont tronquées. La cuticule est finement striée transversalement. Les papilles qui entourent normalement la bouche sont détériorées sur l'unique exemplaire que nous avons eu entre les mains. La coronule externe est formée de lames convergentes, de longueur variable, partant de la paroi interne de la capsule buccale et se rejoignant par leur extrémité libre. Il existe en outre une coronule interne limitant le bord antérieur de la capsule buccale, très courte et annulaire. Les glandes cervicales sont bien développées. L'œsophage, très court, est globuleux ; il est resserré au niveau de l'anneau nerveux qui l'entoure un peu au-dessous de son tiers antérieur ; son plus grand diamètre est situé au niveau de son tiers postérieur. Il existe des valvules à la naissance de l'intestin, dont les cellules sont assez distinctes.

(1) Neveu-Lemaire (M.). - Les Strongylidés du rhinocéros africain (Rhinoceros bicornis). Annales de Parasilologie humaine et comparée, II, no 2, avril 1924, p. 121-153.

\section{Explications de la planche}

\section{Planche VIII}

Pteridopharynx omoensis N.-L. - 1. Mâle, grandeur naturelle. 2. Anatomie du mâle. 3. Bourse caudale. 4. Spicules.

Annales de Parasitologie, T. III, $x^{\circ} 4$. - Oetobre 1925, p. 392-393. 


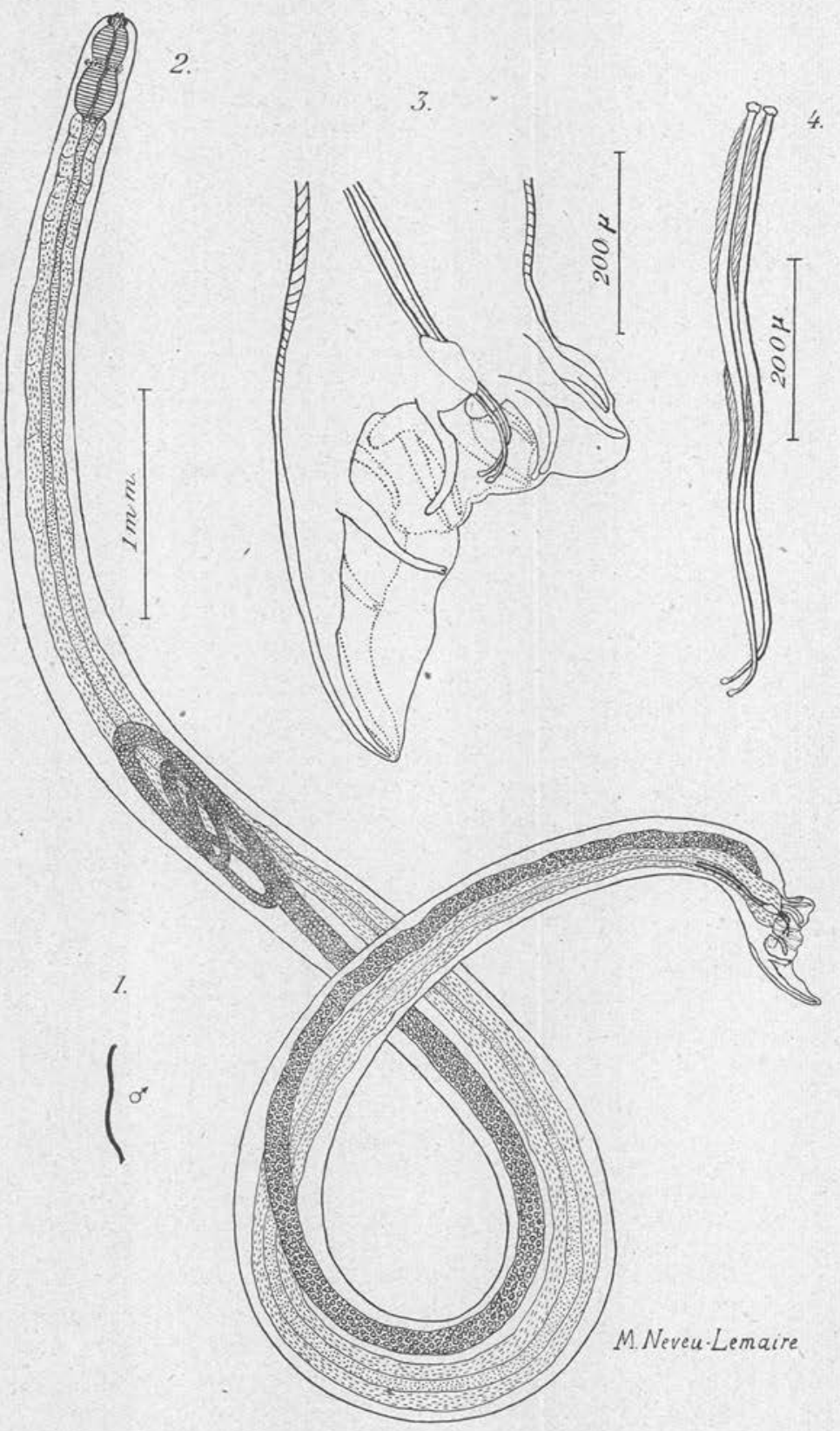

Pteridopharynx omoensis Neveu-Lemaire, 1924 ; mâle. 

Le lobe dorsal de la bourse caudale est plus développé que les lobes latéraux. Les côtes latérales postérieures portent dorsalement un diverticule arrondi. Des trois rameaux de chaque branche de la côte dorsale, les deux externes sont complètement fusionnés, sauf tout à fait à leur extrémité. Les spicules sont égaux, grêles, assez longs et en partie finement striés obliquement ; il existe une pièce accessoire.

DIMENSIONS DE PTERIDOPHARYNX OMOENSIS $\sigma^{\circ}$

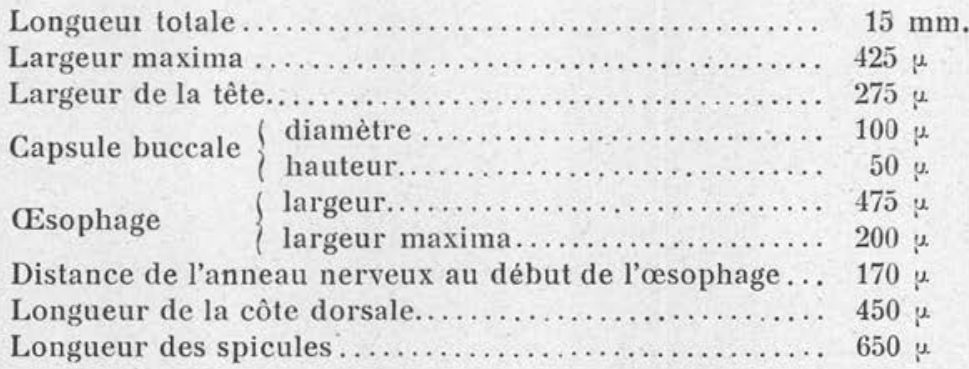

Hôte. - Un seul exemplaire mâle, accompagné d'une demi-douzaine de femelles, a été trouvé dans le gros intestin du rhinocéros d'Afrique, Rhinoceros bicornis L.

Localité. - Ce rhinocéros, autopsié par le professeur E. Brumpt, en 1902, au cours de la Mission du Bourg de Bozas, a été tué dans le voisinage de la rivière Ousnée, affluent du fleuve Omo, dans la région du lac Rodolphe (Afrique orientale).

Laboraloire de Parasitologie de la Facnlté de médecine de Paris. 